\title{
SI-1a
}

\section{Design, construction and experimental investigation of a linear Fresnel concentrator for sustainable energy services in Sub-Saharan Africa}

\author{
Kokouvi Edem N'Tsoukpoe ${ }^{1}$, Gaëlle Kafira Ko², Quentin Falcoz ${ }^{3}$, Yézouma Coulibaly ${ }^{4}$
}

\begin{abstract}
Concentrating solar power (CSP) is considered as one of the promising ways for future sustainable electricity generation, especially in the Sahel region, which is characterized by high direct solar irradiation, but also severe and acute energy poverty. In this paper, we focus on the linear Fresnel system, which it is probably the simplest CSP technology and presents the lowest investment costs. However, it is the less investigated CSP technology and several authors expect significant cost reduction of this technology. Therefore, deeper knowledge on the technology is required. We aim at investigating the coupling of a linear Fresnel system with various energy processes in order to bring out its interests for the Sahel region and, hence, provide sustainable energy services such as electricity generation for rural areas, cooling and refrigeration via sorption cold production, hot water or steam supply for semi-industrial or industrial processes. We have built a linear Fresnel collector of $7.5 \mathrm{~m}^{2}$. The receiver has been designed as a trapezoidal receiver with multi-tubular absorber; it has been experimentally investigated in order to determine its thermal performance, especially the heat loss coefficients. Jatropha curcas oil, a locally produced non-edible vegetable oil is used as heat transfer fluid. The concentrator has been characterised in order to find its optical, thermal and global efficiencies. Paths for the prototype performance improvement have been identified and examined.
\end{abstract}

\section{Introduction}

The average electrification access rate in West African Sahel countries is relatively low compared to the average access rate in West Africa, which is however the Sub-Saharan region with the highest electrification access rate [1]. The situation is worse in rural areas (rural electrification rate: $12 \%$ in average, with high variation from one country to another, where about $60 \%$ of the population actually lives [2]. Concentrating solar power (CSP) is considered as one of the promising ways for future sustainable electricity generation. Apart from electricity generation, the high temperature heat generation may also be imagined for industrial applications that require heat at a temperature level that is not achieved by common solar thermal collectors. Many African countries, especially in the Sahel region, show high potential for CSP plants because of high direct solar irradiation. The initial capital costs, combined with the complexity of the technology, is considered to be the main obstacle to the development of CSP in devel-

\footnotetext{
${ }^{1}$ Dr.-Ing. habil. Kokouvi Edem N'Tsoukpoe, Laboratoire Énergies Renouvelables et Efficacité Énergétique (LabEREE), Institut International d'Ingénierie de l'Eau et de l'Environnement (2iE), Ouagadougou, Burkina Faso, corresponding author : edem.ntsoukpoe@2ie-edu.org / n christedem@2ie-edu.org

${ }^{2}$ Dr.-Ing. Gaëlle Kafira Ko, LabEREE, 2iE, Burkina Faso / PROMES CNRS, France

${ }^{3}$ Dr.-Ing. Quentin Falcoz, PROMES-CNRS, 7 rue du Four Solaire 66120 Odeillo-Font-Romeu, France

${ }^{4}$ Prof. Yézouma Coulibaly, LabEREE, 2iE, Burkina Faso
} 
oping countries $[3,4]$. In addition, to date, CSP technologies have been shown to be economically viable only for high power plants, thus requiring high investment costs. As a result, many of these countries cannot easily invest in this type of facility. Furthermore, the large number of "isolated" rural communities (electrically speaking, for example, there are about 8000 villages in Burkina Faso representing more than $2 / 3$ of the country's population), distant from each other but requiring small powers (a few tens to a few hundred $\mathrm{kW}_{\mathrm{e}}$ ). Finally, the skills required for the implementation for such power plants are not well currently widely spread in Africa. All this leads to opting for small power plants, given the fact that the construction of electricity networks to connect several dispersed localities is very expensive.

The term "concentrating solar power", which actually includes both concentrating solar thermal (CST) and concentrating photovoltaic (CPV) energy conversion, is often used synonymously with "concentrating solar thermal power" [5]. We adopt this restricted definition in this paper. The basic concept of CSP technology is to generate electricity from the driving of a turbine by steam or vapour, in the same way as in conventional gas, coal or nuclear power plants with a major difference: the steam or the vapour is generated using solar thermal energy. Indeed, CSP use mirrors to concentrate direct solar radiation on a point, the receiver, where the temperature increases (typically above $250{ }^{\circ} \mathrm{C}$ ); then, the obtained thermal energy is collected by a heat transfer fluid and delivered to a power block, which is in most cases a Rankine cycle for electricity generation. Currently, a part from concentrating photovoltaic, which is not usually listed, four most common CSP technologies are available: parabolic trough, central receiver system or power tower system, linear Fresnel and parabolic dish.

A literature review on small scale concentrating solar power in the world, which we carried out [6], allowed us to count 35 built or planned plants whose electrical power is between $1 \mathrm{~kW}_{\mathrm{e}}$ and $500 \mathrm{~kW}_{\mathrm{e}}$. Only a very small number of these small scale CSP are actually operating in the field because of a lack of maturity in terms of an optimized system adapted to electrification, especially for rural areas. The operability of these demonstration units in real situations is necessary to assess their relevance. Apart from South Africa, we could not identify small scale CSP in Sub-Saharan Africa. Hence, the development of micro-concentrating solar power ( $\mu$ $\mathrm{CSP}$ ) (electrical power $\leq 100 \mathrm{~kW}_{\mathrm{e}}$ ) for the production of electricity for mini-grid and other sustainable energy services has received particular attention in our Institute. The main advantage of CSP technology over photovoltaic is the possibility of storage to produce electricity at times when the resource is unavailable or insufficient. Thermal storage is indeed much cheaper than direct storage of electricity in batteries and the management of the outputs of such a storage is simpler than that of an electrochemical storage (electrical batteries), not to mention the fire safety issues. Another point of attraction for CSP is the fact that a large part of the components of such plants can be mobilized or manufactured locally with local labour, a fact that offer a room to play on the final costs of production.

Of the four CSP technologies, parabolic dish and parabolic troughs require rounded mirrors (non-planar or curvilinear) while power tower and linear Fresnel systems use flat mirrors. Since flat mirrors are readily available in local markets, power tower and linear Fresnel have been considered as the best choice for local $\mu$-CSP development. The fact that the receiver is fixed receiver avoids the need of rotary joints for the heat transfer fluid [5], since skills for high temperature piping are not well spread in the region whereas the local feasibility is a matter of priority in our research approach. These two technologies are the subject of our current studies: the linear Fresnel for relatively low temperature applications and the power tower plant for relatively high temperature applications. The concept of the proposed power tower has been 
developed in the framework of the CSP4Africa project [7]. In this paper, we focus on the linear Fresnel technology, which has the advantage of being simple with a low wind load, and would require lower investment costs compared to other CSP technologies.

In the similar way as CSP4Africa, which is devoted to power tower technology, we have initiated activities around a linear Fresnel concentrator with high local content. We aim at developing a pilot of a cost-effective $\mu$-CSP plant for sustainable energy services and by designing and experimenting their components using local low cost materials. The purpose is the study of the coupling of a linear Fresnel concentrator with various energy processes to highlight the interest in the Sahel part of West Africa. "Low-tech" is assumed from the start; the idea being to give up the "high performance Concorde" but to which the users cannot resort because of the prohibitive costs. The approach is specifically designed to address energy access challenges in rural areas in the sub-Saharan region:

- Learning by doing approach with use of local skilled mankind

- Local manufacturing of the components of the system by using as much as possible locally available materials

Our ultimate target is the investigating the coupling of a linear Fresnel system with various energy processes in order to bring out its interests for the Sahel region and, hence, provide sustainable energy services such as electricity generation for rural areas, cooling and refrigeration via sorption cold production, hot water or steam supply for semi-industrial or industrial processes.

In this paper, we present the project and report the current achievements. The faced challenges and the options made from the beginning of the project up to now are briefly presented.

\section{The approach to the design of a linear Fresnel collector in Burkina Faso}

The first prerequisite is the evaluation of the relevance of the application on the targeted location, as unlike flat plate photovoltaic (PV), CSP are not relevant everywhere: they are best suited to areas with high direct normal irradiation (DNI: typically more than $2000 \mathrm{kWh} \cdot \mathrm{m}^{-2} \cdot \mathrm{year}^{-}$ ${ }^{1}$ ), high percentage of clear sky days, in locations that do not have high humidity, smog or dust [5]. $17 \%$ of the land area of ECOWAS (Economic Community of West African States) countries received yearly DNI of more than $2000 \mathrm{kWh} \cdot \mathrm{m}^{-2}$ while $38 \%$ enjoys an average yearly DNI of about $1600 \mathrm{kWh} \cdot \mathrm{m}^{-2}$ [8]. Therefore, the West African region, especially the Sahel part, shows a high potential for solar concentrating applications.

A linear Fresnel system consists of two main parts: a concentrator, which constitutes the solar field, and a receiver on which direct solar radiation is concentrated by the reflectors of the concentrators. The heat collected at the receiver is transferred to the target process in order to be converted into the form in which it is used.

We have planned to implement on our campus a pilot of linear Fresnel collector with a capacity of $100 \mathrm{~kW}_{\text {th. }}$. Within the research work, we target a maximum operating temperature of $210^{\circ} \mathrm{C}$. This temperature is relatively low but the target here is to master the process at relatively low temperature level before increasing the temperature level later. As a first step, we have designed and built a prototype of linear Fresnel collector with a capacity of few $\mathrm{kW}_{\text {th }}$. This is prototype is used to acquire a better knowledge of the operation of a linear Fresnel collector. The experimental results from the prototype are collected to supply a model of the pilot that has been developed [9]. This will be used to optimised the design of the final pilot, so the pro- 
totype of linear Fresnel collector is to be seen a tool for the design and optimisation of the projected pilot, which has a modular structure.

The built prototype is shown in Fig. 1 and its characteristics are summarised in Table 1. The used mirrors are the ones readily available on the local market. We have measured their reflectance and found a solar weighted reflectance of 0.72-0.92, depending on the sample [9]. The mirrors have been assembled in five blocks, each of which consists of five rows of mirrors (Fig.2a). The large number of rows is the result of the necessity to reduce blocking and shading losses. In addition, the size of the mirrors has been selected so that they can be easily purchased on the local market and easily handled manually. Initially, each block was thought to be associated to a specific tracking unit but finally, only one tracking unit is use for the whole concentrator.

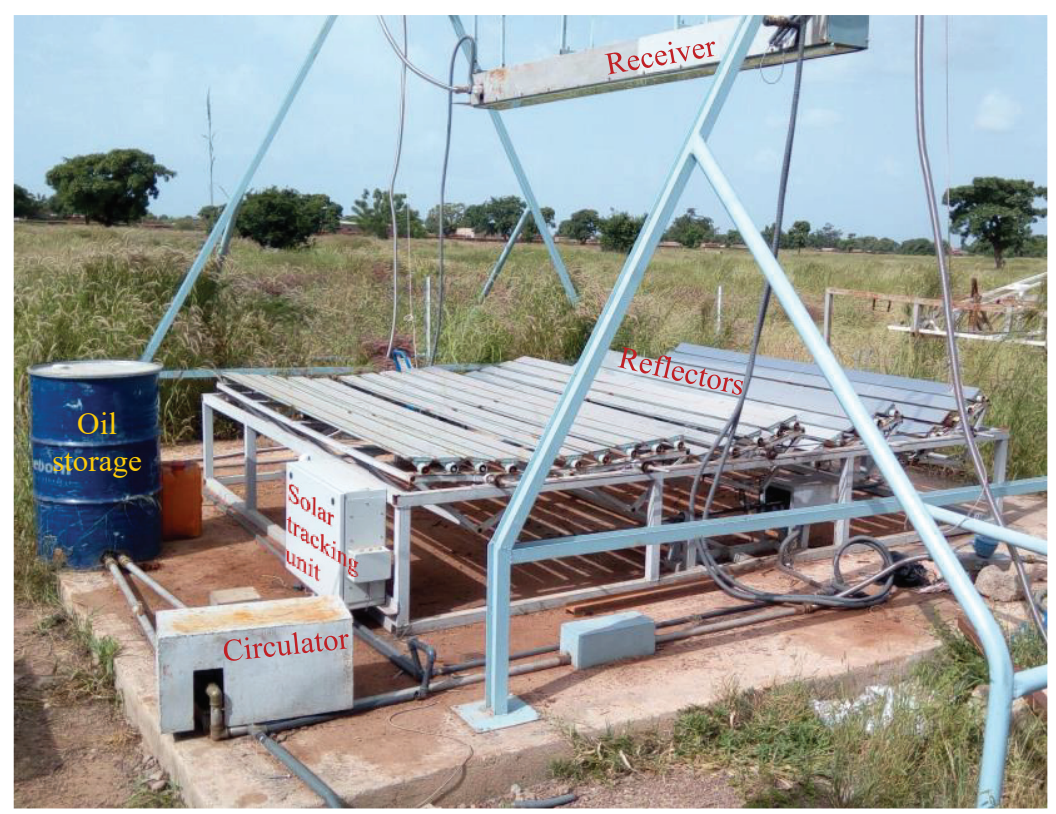

Figure 1. Prototype of linear Fresnel concentrator at 2iE-Kamboinsé.
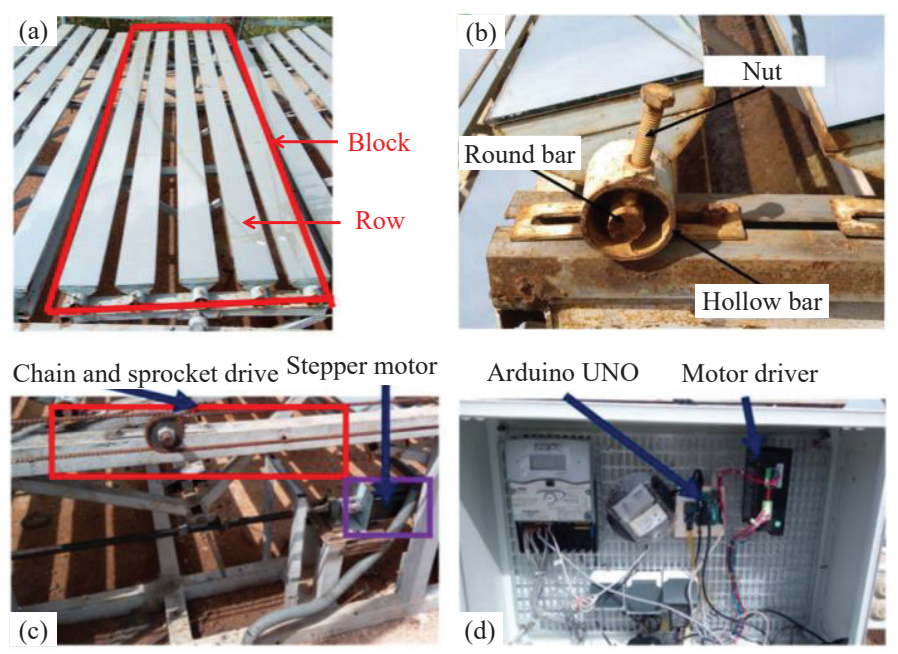

Figure 2. Components of the tracking system of the prototype (a) a block, (b) mirror row tilting mechanism, (c) tracking mechanism and (d) control board. 
SI-1a Design, construction and experimental investigation of a linear Fresnel concentrator for sustainable energy services in Sub-Saharan Africa

\begin{tabular}{|l|l|l|}
\hline \multirow{4}{*}{$\begin{array}{l}\text { Concentrator } \\
\text { frame }\end{array}$} & Dimension $(\mathrm{I} \times \mathrm{w} \times \mathrm{h})$ & $4 \mathrm{~m} \times 3.1 \mathrm{~m} \times 0.7 \mathrm{~m}$ \\
\cline { 2 - 3 } & Area & $12.4 \mathrm{~m}^{2}$ \\
\cline { 2 - 3 } & Material of the frame & Steel \\
\hline \multirow{5}{*}{ Reflecting surface } & Shape of mirrors & Flat \\
\cline { 2 - 3 } & Dimension of each mirror element $(\mathrm{I} \times \mathrm{w} \times \mathrm{h})$ & $0.75 \mathrm{~m} \times 0.10 \mathrm{~m} \times 0.003 \mathrm{~m}$ \\
\cline { 2 - 3 } & Number of mirrors elements & 100 \\
\cline { 2 - 3 } & Total $($ reflecting) area of the mirrors & $7.5 \mathrm{~m}^{2}$ \\
\cline { 2 - 3 } & Number of block of mirrors & 5 \\
\cline { 2 - 3 } & Total (reflecting) area of a block of mirrors & $1.5 \mathrm{~m}^{2}$ \\
\cline { 2 - 3 } & Reflectance of mirrors & $0.72-0.92$ \\
\hline \multirow{5}{*}{ Receiver (overall) } & Shape & Trapezoidal \\
\cline { 2 - 3 } & Size of the receiver $(\mathrm{I} \times \mathrm{w} \times \mathrm{t})$ & $3.2 \mathrm{~m} \times 0.28 \mathrm{~m} \times 0.2 \mathrm{~m}$ \\
\cline { 2 - 3 } & Size of the glass $(\mathrm{I} \times \mathrm{w} \times \mathrm{t})$ & $3.2 \mathrm{~m} \times 0.28 \mathrm{~m} \times 0.003 \mathrm{~m}$ \\
\cline { 2 - 3 } & Glass transmittance $($ solar weighted) & 0.75 \\
\cline { 2 - 3 } & Insulation material & Glass wool \\
\cline { 2 - 3 } & Material of the frame & Steel \\
\hline \multirow{5}{*}{ Absorber } & Number of tubes & 7 \\
\cline { 2 - 3 } & Diameter of a tube & $16 \mathrm{~mm}$ \\
\cline { 2 - 3 } & Length of the absorber & $3.0 \mathrm{~m}$ \\
\cline { 2 - 3 } & Surface of the absorber & $0.336 \mathrm{~m}^{2}$ \\
\cline { 2 - 3 } & Geometric concentration ratio & 22 \\
\cline { 2 - 3 } & Material of the tubes & Copper \\
\cline { 2 - 3 } & Painting & Solkote HI/SORB-II \\
\cline { 2 - 3 } & Absorptance of the absorber (solar weighted) & 0.87 \\
\cline { 2 - 3 } & Emissivity of the absorber & 0.23 \\
\hline
\end{tabular}

Table 1. Summary of the characteristics of the prototype of linear Fresnel collector.

For the receiver, a horizontally downward receiver design has been adopted. It is a multi-tubes trapezoidal cavity receiver (Fig.3). This kind of receiver, which is preferred in low and medium temperatures up to $300{ }^{\circ} \mathrm{C}$ [10], has lower cost compared to evacuated tube receivers and is simple to be built. There is no absorber plate in front of the tubes so that they directly absorb the solar irradiation from the reflectors. Hence, the absorber consists of seven copper pipes with external diameter of $16 \mathrm{~mm}$. To increase the absorptance of the absorber, a selective solar absorbing paint (Solkote HI/SORB-II [11]) has been applied on the copper tubes. A mirror is installed on each side of the absorber to operate as a secondary reflector (Fig.3).

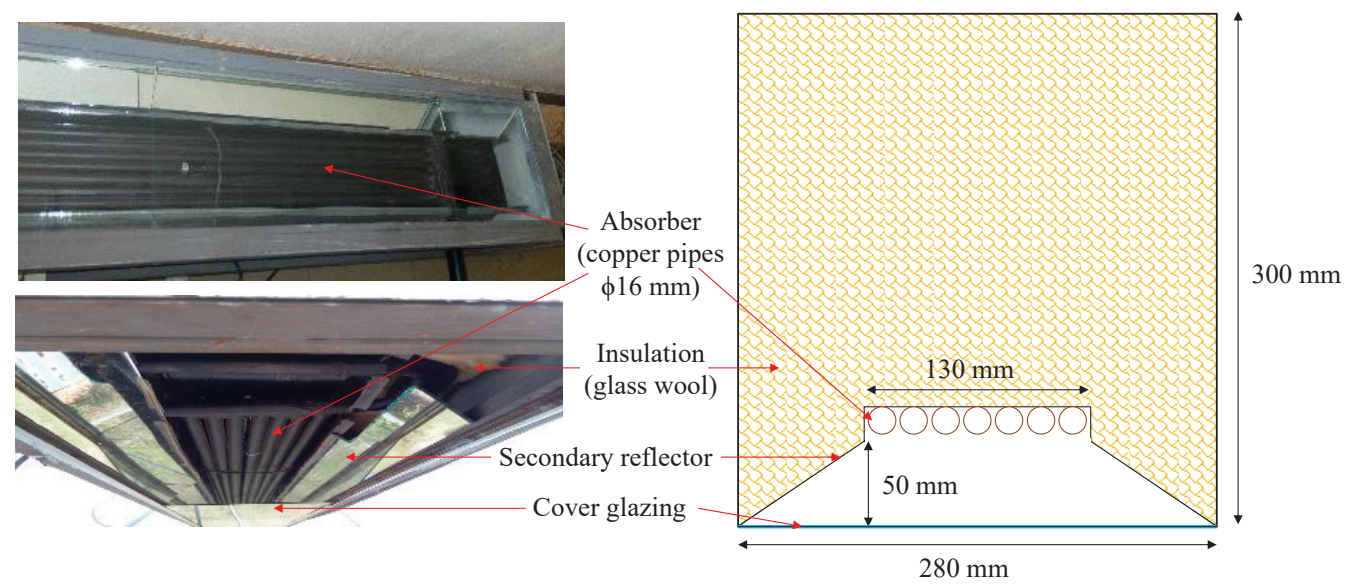

Figure 3. Detail view of the receiver. 
A single axis north-south oriented tracking system was designed to drive the system using a single stepper motor for the whole concentrator. The stepper motor is controlled with an Arduino UNO via a microcontroller board (Fig.2d). The tracking system is an open loop operating with the solar position algorithm (SPA) [12], which has replaced the Michalsky's algorithm that was originally used but led to some accuracy challenges. During the solar tracking, all the blocks rotate at the same velocity thanks to the chain and sprocket drive (Fig.2c). The stepper motor is coupled with a threaded rod that is connected to the central block with nuts (Fig.2b,c). For the heat transfer fluid and the thermal storage material, we consider now the promotion of a vegetable oil that is locally produced: Jatropha curcas crude oil (JaCCO). The main advantage of a possible use of JaCCO as thermal storage or heat transfer fluid is that the oil is locally produced and available at low cost [13]. Since JaCCO has never been used as heat transfer or thermal storage medium, we have performed some preliminary studies to check its potential to be used as a heat transfer fluid or thermal storage material in CSP plants. First results show that Jatropha curcas oil is a promising heat transfer fluid and storage material for CSP plants $[13,14]$. The main drawback of using oils is the fact that they are flammable.

In the case of use of the linear Fresnel collector for electricity generation, a power block is needed. It has been decided to acquire a commercially available ORC as a local development of such a unit is not foreseen at this stage. Given the Sahel context, a dry cooler has been selected with the ORC in order to avoid water cooling tower that would result in significant water consumption.

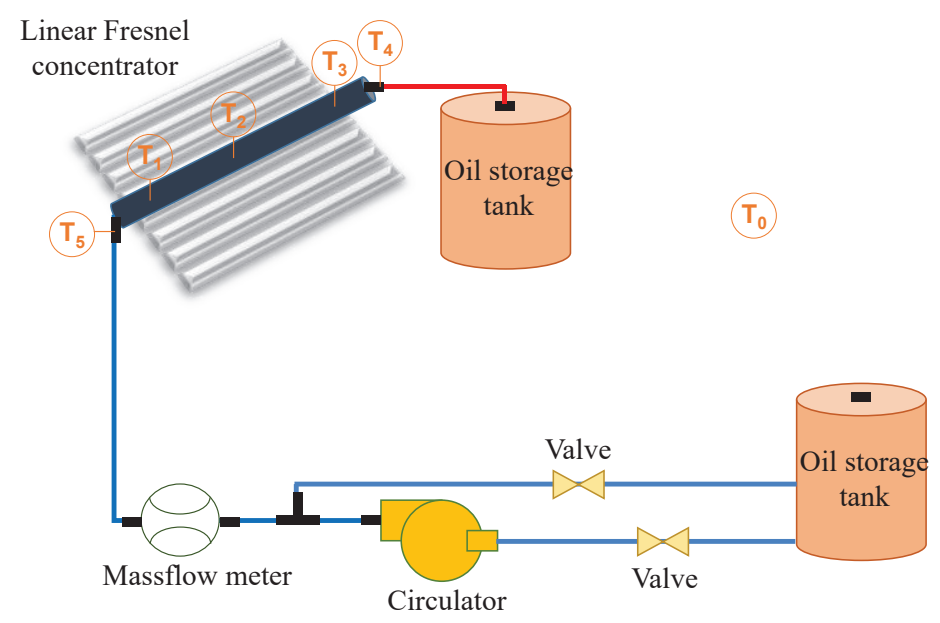

Figure 4. Experimental set-up

\section{Experimental results}

\subsection{Experimental set-up}

The prototype of linear Fresnel collector as described above is operated under various conditions in order to quantify its thermal losses. The prototype allows the adjustment of the position of the receiver at various heights above the concentrator. For the tests, the height of the receiver above the concentrator has been set to $3 \mathrm{~m}$. The prototype has been instrumented, to be able to measure temperatures (accuracy: $0.1^{\circ} \mathrm{C}$ ) at the inlet and outlet of the receiver (Fig.4). The mass flow rate of oil circulating in the receiver was measured using a mass flow 
meter (F050S239CQFZFZZZZ, EMERSON, uncertainty: $\pm 1 \%$ ) and the values are recorded every 5 min. Beam solar irradiance was measured by pyrheliometer (CHP1 KIPP and ZONEN) and with data record every minute.

\subsection{Experimental procedure}

The experimental procedure to determine the overall heat loss coefficient of the receiver is similar to the one described by Singh et al. [15]. Jatropha oil was heated in an oil storage tank using a gas burner and circulated at a controlled flow rate through the absorber tubes. The concentrator is covered by a tarpaulin to avoid reflection of any solar irradiance, from the concentrator, on the receiver. The oil flow rate was kept constant during the whole experiment. In order to estimate the heat losses at different temperatures, the tests have been performed at pre-defined receiver inlet temperatures. Hence, for any test, the oil is heated until the selected temperature while a manual stirrer is used to promote temperature homogeneity in the oil storage tank. The useful data are the one recorded during a steady state i.e. when the temperature at the inlet of the absorber and the absorber wall temperature remain practically constant (changes $<1^{\circ} \mathrm{C}$ ) for a duration equals to 4 times the residence time of the fluid in the absorber. Note that there was no control of the air flow rate along the bottom of the absorber during the test so that it was subject to the speed of wind. The decrease in temperature observed through the passage of oil through the receiver gives the magnitude of the heat loss $Q_{l}$, which may be estimated as follows (1):

$Q_{l}=m C_{p}\left(T_{i}-T_{o}\right)$

where $m$ is the mass flow rate heat transfer fluid and $C_{p}$ is the specific heat capacity of the heat transfer fluid; $T_{i}$ and $T_{o}$ are the heat transfer fluid temperature at the receiver s' inlet and outlet, respectively.

The overall heat loss coefficient $U_{l}$ was then derived as follows (2) [15]:

$U_{l}=Q_{l} /\left[A_{a b s}\left(T_{m}-T_{a m b}\right)\right]$

where $T_{m}=\left(T_{i}+T_{o}\right) / 2$.

The receiver is tested over a temperature range of $50{ }^{\circ} \mathrm{C}$ to $100^{\circ} \mathrm{C}$ because the used pump was not suitable for temperature higher than $100{ }^{\circ} \mathrm{C}$.

\subsection{Results and discussion}

Figure 5 shows the evolution of temperature for a test during which the receiver inlet temperature was $87 \pm 0.5{ }^{\circ} \mathrm{C}$. The resident time during test was $4 \mathrm{~min}$. From 11:34 to 11:42, i.e. during $8 \mathrm{~min}$, the inlet and outlet temperatures are relatively constant so that an average thermal loss may be evaluated to $223 \mathrm{~W}$ (Fig. 5).

After several tests, the obtained overall heat losses for individual differences of the oil mean temperature and ambient temperature are depicted in Fig. 6.

Obviously, heat losses increase with the temperature difference between the oil and the ambient temperature. However, the values obtained show a cloud that may question the repeatability of the results, especially around a temperature difference of $40{ }^{\circ} \mathrm{C}$. This is probably due, among other things, to the fluctuation of wind velocity as the tests was conducted under outdoor conditions. Therefore, future tests should take care for a better control of the ambient conditions. 


\subsection{Estimation of the capacity of the concentrator}

The capacity of the single concentrator may be estimated based on measured data using equation (3):

$Q_{u}=\eta_{o p t} \cdot I \cdot A_{c}-U_{r} \cdot A_{a b s} \cdot\left(T_{m}-T_{a m b}\right)$

where $I$ is the solar direct normal irradiance, $A_{c}$ is the surface area of the reflecting area, $A_{a b s}$ is the surface area of the absorber, $U_{r}$ is the heat loss coefficient of the absorber, $T_{m}$ and $T_{a m b}$ are the absorber and ambient temperatures, respectively. $\eta_{\text {opt }}$ is the optical efficiency and is given by Equation (4):

$\eta_{\text {opt }}=\rho \cdot \tau \cdot \gamma \cdot \alpha \cdot K$

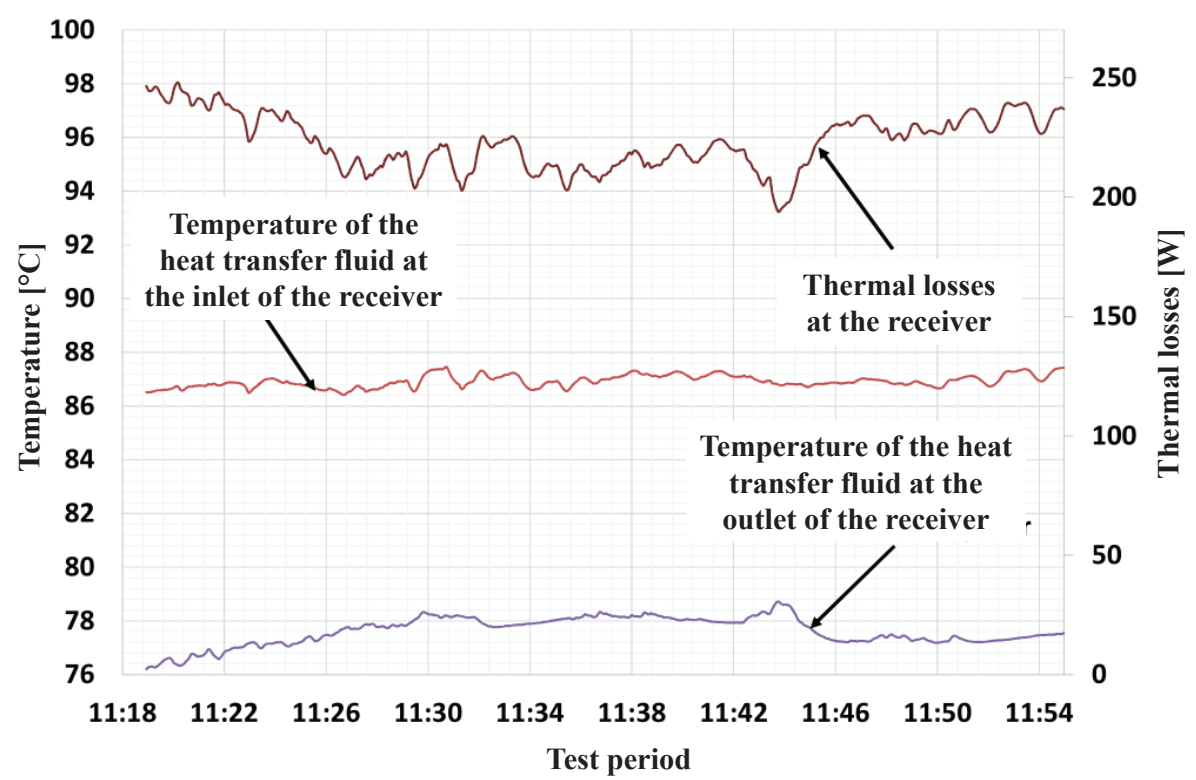

Figure 5. Temperatures and heat losses during a test.

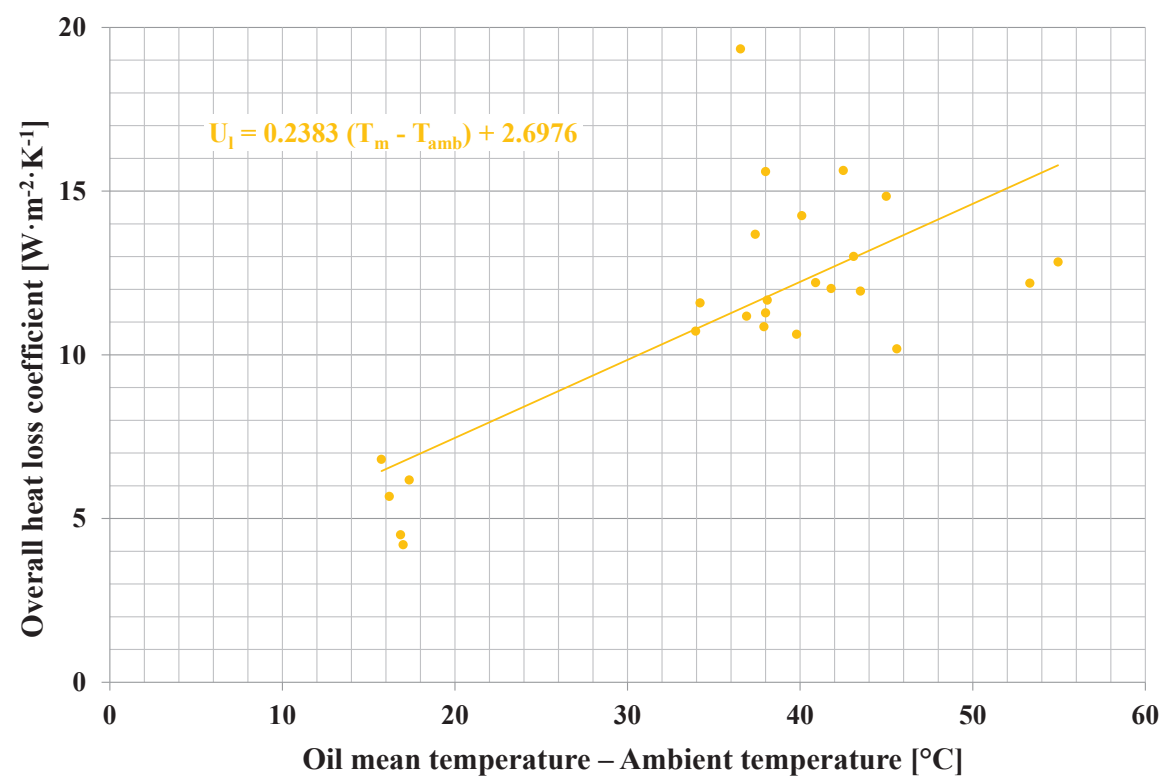

Figure 6. Overall heat loss coefficient as a function of the difference of the oil mean temperature and ambient temperature. 
where $\rho$ is the mirror reflectance, $\tau$ is the transmittance of the receiver glass, $\alpha$ is the absorbance of the absorber, $K$ is the incidence angle modifier, $\gamma$ is the intercept factor, which accounts various optical losses such as tracking error, shading and blocking.

$\rho, \tau$ and $\alpha$ have been already measured [9]. The heat loss coefficient may be estimated based on data in Fig. 6. For this first estimate, we assume an intercept factor of 1 . The incidence angle modifier $K$ and the solar beam I depend on the assumed design conditions. The majority of the studies use the conditions at the vernal equinox or the summer solstice [16]. In the present case, we consider, at solar noon, both of these conditions and also the day of the solar zenith passage (i.e. when the declination equals the latitude of the collector $=12^{\circ} 27^{\prime} \mathrm{N}, 1^{\circ} 33^{\prime} \mathrm{W}$ ). This is April $23^{\text {th }}$, when we consider its occurrence in spring or summer. $K$ is the product of the longitudinal incidence angle modifier and the transversal incidence angle modifier, are derived from ray-tracing for our prototype [9]. The values of DNI are the average of three years (20112013) measured data at the site of $2 \mathrm{iE}$ Kamboinsé. To estimate the heat losses, we consider a temperature change of $100{ }^{\circ} \mathrm{C}$ in the receiver, that is an inlet temperature of $110{ }^{\circ} \mathrm{C}$ and an outlet temperature of $210^{\circ} \mathrm{C}$. The results are presented in Table 2.

\begin{tabular}{|l|l|l|l|}
\hline Design point & Vernal equinox & Sun at the zenith & Summer solstice \\
\hline DNI [W·m-2] & 460 & 530 & 490 \\
\hline Ambient temperature $\left[{ }^{\circ} \mathrm{C}\right]$ & 41.6 & 41.8 & 34.3 \\
\hline paTY & 0.535 & 0.535 & 0.535 \\
\hline $\mathrm{KL}$ & 0.83 & 1 & 0.84 \\
\hline $\mathrm{KT}$ & 1 & 1 & 1 \\
\hline Incidence angle modifier K & 0.83 & 1 & 0.84 \\
\hline Estimated UI [W·m-1·K-2] & 31 & 31 & 33 \\
\hline Heat losses QI [W] & 1262 & 1226 & 1379 \\
\hline Useful heat Qu [W] & 270 & 901 & 273 \\
\hline
\end{tabular}

Table 2. Estimation of the capacity of the linear Fresnel collector under various design point conditions.

The analysis shows that the capacity of the prototype is about $0.3 \mathrm{~kW}$, based on the performance at vernal equinox and summer solstice. It appears that the heat losses are relatively large compared to the useful heat (Table 2). This is either due to the design of the collector or to the correlation used to estimate the heat losses. Indeed, the correlation has been derived from the results of the thermal losses of the receiver, which show however, some repeatability issues, as discussed in the previous section. Furthermore, the correlation has been extrapolated to a temperature level that has not been explored during the tests due the fact that the used pump could not perform above $100{ }^{\circ} \mathrm{C}$. It is therefore necessary to implement the tests at higher temperature while ensuring their repeatability and accuracy.

\section{Conclusion}

The designed prototype of a linear Fresnel concentrator has been presented and discussed. It has been constructed and has been experimentally investigated in order to quantify its thermal losses. This prototype represents a research and development tool that offers an opportunity to demonstrate the feasibility of a micro-CSP plant in West African Sahel by analysing the system through various aspects such as capacity building, technical and economic issues. Its replication potential, if used, would generate local income and jobs, contributes to energy-water- 
food security and poverty alleviation. The capacity of the prototype at the moment could not be accurately estimated due to some experimental limitations. Further experiments are required to overcome these limitations.

\section{References}

[1] International Energy Agency (IEA). World Energy Outlook (WEO) 2018 Electricity Database: Electricity access in 2017. International Energy Agency (IEA); 2018]. Available from: www.iea.org/media/sdg/WEO2018-Electricity-Database.xlsx.

[2] Worldometers. Population of Western Africa (2019) - Worldometers 2019 [cited August 30, 2019]. Available from: www.worldometers.info/world-population/western-africapopulation/.

[3] Amer M, Daim TU. Selection of renewable energy technologies for a developing county: A case of Pakistan. Energy Sustain Dev 2011;15:420-35.

[4] Ziuku S, Seyitini L, Mapurisa B, Chikodzi D, van Kuijk K. Potential of concentrated solar power (CSP) in Zimbabwe. Energy Sustain Dev 2014;23:220-7.

[5] Lovegrove K, Csiro WS. 1 - Introduction to concentrating solar power (CSP) technology. In: Lovegrove K, Stein W, editors. Conc. Sol. Power Technol., Woodhead Publishing; 2012, p. 3-15 [cited February 25, 2015]. Available from: www.sciencedirect.com/science/article/pii/B9781845697693500017.

[6] Seshie YM, N'Tsoukpoe KE, Neveu P, Coulibaly Y, Azoumah YK. Small scale concentrating solar plants for rural electrification. Renew Sustain Energy Rev 2018;90:195-209.

[7] N'Tsoukpoe KE, Azoumah KY, Ramde E, Fiagbe AKY, Neveu P, Py X, et al. Integrated design and construction of a micro-central tower power plant. Energy Sustain Dev 2016;31:1-13.

[8] Ramde EW, Azoumah Y, Brew-Hammond A, Rungundu A, Tapsoba G. Site ranking and potential assessment for concentrating solar power in West Africa. Nat Resour 2013:4:146-53.

[9] Ko KG. Study and dynamic modelling of linear Fresnel concentrator [Étude et modélisation dynamique d'un concentrateur à miroir linéaire de Fresnel]. PhD. Institut International d'Ingénierie de l'Eau et de l'Environnement, 2019.

[10] Bellos E. Progress in the design and the applications of linear Fresnel reflectors - A critical review. Therm Sci Eng Prog 2019;10:112-37.

[11] SOLEC-Solar Energy Corporation. Solkote selective solar absorbing paint technical specifications. 2019 [cited August 31, 2019]. Available from: www.solec.org/solkote/solkotetechnical-specifications/.

[12] Reda I, Andreas A. Solar Position Algorithm for solar radiation applications. Colorado: National Renewable Energy Laboratory; 2008]. Available from: www.nrel.gov/docs/fy08osti/34302.pdf.

[13] Kenda ES, N'Tsoukpoe KE, Ouédraogo IWK, Coulibaly Y, Py X, Ouédraogo FMAW. Jatropha curcas crude oil as heat transfer fluid or thermal energy storage material for concentrating solar power plants. Energy Sustain Dev 2017;40:59-67.

[14] Gomna A, N'Tsoukpoe KE, Le Pierrès N, Coulibaly Y. Thermal stability of a vegetable oil-based thermal fluid at high temperature. Afr J Sci Technol Innov Dev 2020;0:1-10.

[15] Singh PL, Sarviya RM, Bhagoria JL. Thermal performance of linear Fresnel reflecting solar concentrator with trapezoidal cavity absorbers. Appl Energy 2010;87:541-50.

[16] Wirz M, Roesle M, Steinfeld A. Design point for predicting year-round performance of solar parabolic trough concentrator systems. J Sol Energy Eng 2013. 